\title{
BMJ Open Intermarriage and COVID-19 mortality among immigrants. A population-based cohort study from Sweden
}

\author{
Siddartha Aradhya (D) , ${ }^{1}$ Maria Brandén, ${ }^{1,2}$ Sven Drefahl, ${ }^{1}$ Ognjen Obućina, ${ }^{3}$ \\ Gunnar Andersson, ${ }^{1}$ Mikael Rostila, ${ }^{4}$ Eleonora Mussino, ${ }^{1}$ Sol Pía Juárez (1) ${ }^{4}$
}

To cite: Aradhya S, Brandén M, Drefahl S, et al. Intermarriage and COVID-19 mortality among immigrants. A population-based cohort study from Sweden. BMJ Open 2021;11:e048952. doi:10.1136/ bmjopen-2021-048952

- Prepublication history and additional supplemental material for this paper are available online. To view these files, please visit the journal online. (http://dx.doi.org/10.1136/ bmjopen-2021-048952).

Received 19 January 2021 Accepted 28 July 2021

Check for updates

(c) Author(s) (or their employer(s)) 2021. Re-use permitted under CC BY. Published by BMJ.

${ }^{1}$ Stockholm University Demography Unit (SUDA), Department of Sociology, Stockholm University, Stockholm, Sweden

${ }^{2}$ The Institute for Analytical

Sociology (IAS), Linköping

University, Linkoping, Sweden

${ }^{3}$ Institut national d'études démographiques (INED), Aubervilliers, France

${ }^{4}$ Department of Public Health Sciences, Stockholm University, Stockholm, Sweden

Correspondence to

Dr Sol Pía Juárez;

sol.juarez@su.se

\section{ABSTRACT}

Objectives To evaluate the role of language proficiency and institutional awareness in explaining excess COVID-19 mortality among immigrants.

Design Cohort study with follow-up between 12 March 2020 and 23 February 2021.

Setting Swedish register-based study on all residents in Sweden.

Participants 3963356 Swedish residents in coresidential unions who were 30 years of age or older and alive on 12 March 2020 and living in Sweden in December 2019.

Outcome measures Cox regression models were conducted to assess the association between different constellations of immigrant-native couples (proxy for language proficiency and institutional awareness) and COVID-19 mortality and all other causes of deaths (2019 and 2020). Models were adjusted for relevant confounders. Results Compared with Swedish-Swedish couples (1.18 deaths per thousand person-years), both immigrants partnered with another immigrant and a native showed excess mortality for COVID-19 (HR 1.43; 95\% $\mathrm{Cl} 1.29$ to 1.58 and $\mathrm{HR} 1.24 ; 95 \% \mathrm{Cl} 1.10$ to 1.40 , respectively), which translates to 1.37 and 1.28 deaths per thousand person-years. Moreover, similar results are found for natives partnered with an immigrant (HR 1.15; 95\% Cl 1.02 to 1.29), which translates to 1.29 deaths per thousand person-years. Further analysis shows that immigrants from both high-income and low-income and middleincome countries (LMIC) experience excess mortality also when partnered with a Swede. However, having a Swedish-born partner is only partially protective against COVID-19 mortality among immigrants from LMIC origins. Conclusions Language barriers and/or poor institutional awareness are not major drivers for the excess mortality from COVID-19 among immigrants. Rather, our study provides suggestive evidence that excess mortality among immigrants is explained by differential exposure to the virus.

International evidence has shown that immigrants and ethnic minorities are disproportionately at risk of severe COVID-19 complications and death. ${ }^{1-13}$ In the context of an ongoing pandemic, an effort to understand the causes for why some groups are more affected is a public health priority. ${ }^{14-17}$

\section{Strengths and limitations of this study}

- This study uses total population data with all deaths (from COVID-19 and other causes) in Sweden from 12 March 2020 to 23 February 2021.

- We identified the origin of co-resident couples to evaluate the role of language proficiency and institutional awareness (eg, healthcare system) in explaining excess COVID-19 mortality among immigrants.

- We compare COVID-19 mortality with all other causes of death during the pandemic and all-cause mortality 1 year prior to evaluate the relative impact of the pandemic within each group.

- The analyses do not include information on occupation, however the most vulnerable individuals are beyond retirement age.

Among these groups, excess mortality has been suggested to be the result of differential exposure (eg, high-risk occupations or overcrowded accommodation), susceptibility (eg, pre-existing conditions) and language barriers and access to healthcare ${ }^{18-20}$ Recent studies, however, suggest that immigrants and minorities maintain an excess mortality even after controlling for socioeconomic status and housing conditions. ${ }^{321}$ Yet there is paucity of evidence on the role of language barriers and institutional awareness in explaining the COVID-19 excess mortality experienced by immigrants.

Sweden took a distinct approach to dealing with the COVID-19 pandemic as compared with other Western countries by not implementing lock downs or mask mandates and instead relied largely on recommendations. The authorities justified implementing a relatively less rigid approach by arguing that Swedes have a high level of trust in their institutions and as such follow governmental recommendations. ${ }^{22} 23$ The strategy relied primarily on public health advice (regarding hygiene routines, social distancing and suspension from work, school or daycare in case of minor 
symptoms) in lieu of mandates which are not permitted under Swedish law. ${ }^{22}$ The effectiveness of the adopted strategy strongly depends on the ability of all members of the society to understand the recommendations, which is a basic condition for their adherence. Under this rationale, it is unsurprising that excess mortality observed among immigrants ${ }^{24}$-especially concentrated among those with more distant origins-could be interpreted as a consequence of lower adherence to recommendations and/or related factors.

More specifically, it has been argued that immigrants may, as a result of inadequate language proficiency and institutional awareness, have a poor understanding of the healthcare system and of the recommendations during the COVID-19 pandemic putting them at higher risk of exposure and vulnerability to the virus. Analysing intermarried immigrants present a unique opportunity to generate evidence for this explanation.

Within the field of immigrant integration, intermarriage has been considered the ultimate stage of acculturation $^{25-27}$ and is, both, a marker of and facilitator for integration. Marrying a native is strongly related to language abilities, knowledge of the host country's institutions and social practices as well as the ethnic composition of one's social circle. As a result, intermarriage reflects the narrowing of sociocultural distance between ethnic Swedes and immigrants, which renders it an ideal measure to evaluate the role of understanding and awareness of recommendations from Swedish authorities as explanations for the excess COVID-19 mortality among immigrants.

If understanding and awareness of recommendations (language in primis) explain the excess mortality, immigrants partnered with a Swede and, in particular, Swedes partnered with an immigrant should have similar mortality to Swedes partnered with a Swede. To this end, the aim of this study is to examine the association between sociocultural integration and COVID-19 mortality by examining native-immigrant couple dyads-a well-regarded measure that has been shown to be a marker and facilitator of integration.

\section{METHODS}

\section{Study population}

An observational cohort study was conducted using Swedish register data. The study includes all Swedish residents who were 30 years of age or older and were cohabiting with another adult who was at least 30 years of age and alive on 12 March 2020, residing in Sweden in December 2019 ( $\mathrm{n}=4019$ 418). This age restriction was established to ensure co-resident individuals were family members and not flat mates. The follow-up period was 12 March 2020 up until 23 February 2021. We excluded individuals who had not lived in Sweden in the two prior years $(n=40515)$, because they could not be linked to all records of data. In addition, we excluded individuals with missing data on country of birth $(n=142)$ and income $(\mathrm{n}=15405)$ of either partner. The final study population consists of 3963356 individuals (18.5\% immigrants) (figure 1).

\section{Patient and public involvement}

No patient was involved.

\section{Data}

We use information from several Swedish administrative registers linked through personal identity numbers that are unique to each person with legal residence in Sweden. Data on deaths were retrieved from the Cause of Death Register. Socioeconomic and demographic variables (income, education, number of children and region of residence) were drawn from the Longitudinal Integrated Database for Health Insurance and Labour Market Studies (LISA), and residential information (type and crowdedness of the dwelling) were drawn from the

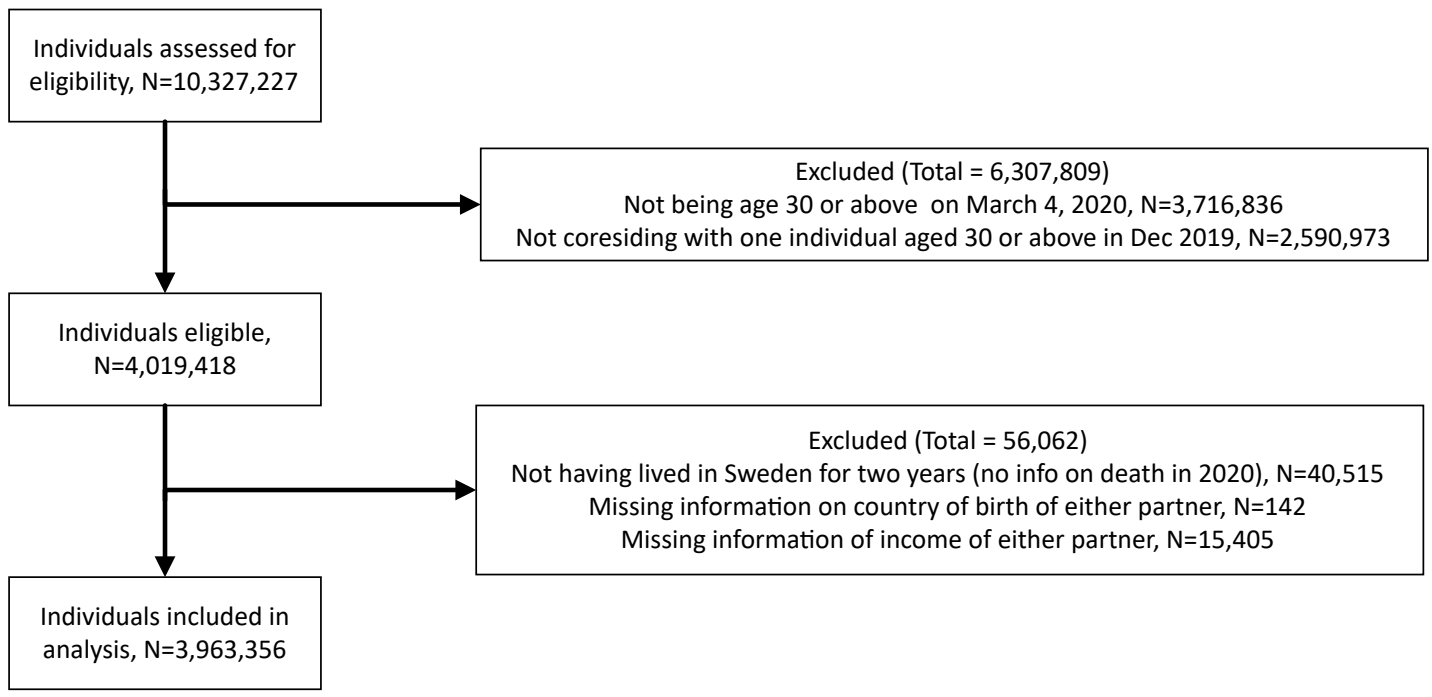

Figure 1 Selection flow and final sample. 
Dwelling Register. All covariates in our study are timeconstant and either measured at the end of 2019 (all variables at the household and neighbourhood level) or 2018 (highest education attained, sum of the individual net incomes of the two co-resident adults, total number of individuals in the household under 30). Information on age, sex, country of birth and immigrant density in the neighbourhood stem from the Total Population Register. It is important to note that all individuals registered in Sweden are entitled to healthcare access.

\section{Study variables}

COVID-19 mortality was identified by the Swedish National Board of Health and Welfare (Socialstyrelsen), the agency responsible for the Cause of Death Register. COVID-19 mortality was identified using the following International Classification of Diseases (ICD) codes for the underlying cause of death: U07.1 (3915 deaths), U07.2 (127 deaths) and B34.2 (2 deaths); for 522 more deaths ICD codes U07.1, U07.2 or B34.2 were listed as contributing causes of death, excluding mortality from all other causes of death (30374 deaths). Given the timeliness of the data, the assignment of the underlying cause of death should be understood as preliminary.

Immigrant-native couple types were created by combining information from the Dwelling and the Total Population Registers to create the couple type which include two individuals of at least 30 years of age co-residing in the same household. The variable is classified into the following four ego-partner categories using information on country of birth: (i) native-native, (ii) native-immigrant, (iii) immigrant-native and (iv) immigrant-immigrant. We chose (i) native-native couples as the reference group for our analyses as they (a) constitute the largest category among all groups considered and (b) represent the institutional awareness and language of the host population from which we expect other groups to deviate. We further disaggregated the groups by immigrant's origins defined according to the World Bank classification based on the Gross National Incomes per capita using the WB Atlas method ${ }^{28}$ as high-income countries (HIC) and low-income and middle-income countries (LMIC).

We derived individual income and calculated the sum of the two partners' net incomes (household), categorised into tertiles based on all adult residents of Sweden. We derived education data from Swedish Educational Registers and categorise our population into four categories: those with primary schooling, secondary schooling, postsecondary education and those with missing information on education. Missing information on education is generally very low but $88 \%$ of those with missing education are immigrants. We additionally performed multiple imputation to test how the missing values for education impact our results (see online supplemental appendix figure S1). In addition, we dropped all missing categories to assess whether the distributions of covariates were affected by missing values (see online supplemental appendix table
S1). From the Swedish Dwelling Register, we accessed information on size of the dwelling and a unique dwelling code which enables us to link individuals who live together in a household and determine co-residence. In addition to define couples, we use this information to create: the number of individuals per square metre in the household (with a separate category for a small group of individuals, due to missing information on square metres in some detached houses), the number of individuals living in the household under the age of 30 and dwelling type (multifamily, single family or care home). We include in our model also the share of immigrants in the local neighbourhood, DeSO (a smaller subdivision of administrative areas based on demographic characteristics produced by the Swedish administrative statistics).

\section{Statistical analysis}

We conducted Cox proportional hazards regressions (using age as the timescale) to estimate HR and 95\% CI for the association between immigrant-native couple type and COVID-19 mortality. Individuals exited the study by (1) dying between 12 March 2020 and 23 February 2021, or (2) being alive on 23 February 2021. We estimated two separate regressions estimating the cause-specific hazard of dying from COVID-19, right-censoring all individuals that die from other causes and (2) the cause-specific hazard of dying from other causes than COVID-19, rightcensoring all individuals that die from COVID-19. In addition, we conducted Cox regressions for dying from all causes of death that occurred between 12 March 2019 and 23 February 2020 (31 653 deaths) - the same period we observe COVID-19 deaths 12 contiguous months prior to the start of the pandemic. Since mortality from COVID-19 and other causes of deaths during the study window are not fully independent of each other, our estimates for all-cause mortality between 12 March 2019 and 23 February 2020 were used to evaluate the robustness of our estimates for mortality during the pandemic. In addition, the comparison between all-cause mortality 1 year prior and mortality from causes other than COVID-19 during the pandemic, by immigrant-native couple type, will allow us to examine whether the latter has a distinctive role in relation to the pandemic.

Two models were estimated: (1) a simple model with age as the time scale adjusted for sex and (2) the same model with further adjustments. In the latter analysis, we adjust for education, neighbourhood immigrant density and region of residence fixed-effects that are confounders, as well as factors that are on the causal pathway that have been previously used to explain the excess mortality of immigrants (ie, number of individuals in the household below the age of 30 years, dwelling type, square metres per person in the dwelling, household income). In addition, we conducted two sensitivity analyses. One in which we examined the partner's origin among Swedish-migrant partnerships (HIC or LMIC) to check whether patterns are consistent across groups and, a second, in which we excluded all individuals born in Sweden with at least one 
foreign-born parent. All analyses were conducted using Stata Statistical Software: Release 16 (StataCorp, College Station, Texas, USA).

\section{RESULTS}

During the 3759610 person-years of observation, 4564 COVID-19 deaths occurred in our study population between 12 March 2020 and 23 February 2021. Table 1 shows the distribution of population at risk and deaths by all covariates. In our population, $6.09 \%$ of individuals are in immigrant-native couples. Native-native couples show the lowest deaths per thousand person-years $(1.18 / 1000)$, whereas all other couple types show higher death rates of COVID-19 mortality (approximately 1.3-1.4 per thousand person-years). Of the study population, $6.55 \%$ of COVID-19 deaths were attributed to native-immigrant mixed couples and $14.04 \%$ to immigrant-immigrant couples.

Figure 2 displays mortality risks from COVID-19, all other causes of death during the pandemic and all-causes of death 1 year prior across couple types with native-native as the reference (see online supplemental appendix table S2 for estimates). Panel A presents models adjusted for age and sex and panel $\mathrm{B}$ presents the estimates including adjustments. In A, individuals in immigrant-immigrant couples show the highest HR of dying from COVID-19 (HR 2.47; 95\% CI 2.27 to 2.69) and those in native-native couples the lowest (reference group) while natives (HR 1.40; $95 \%$ CI 1.25 to 1.58 ) and immigrants (HR 1.50; $95 \%$ CI 1.33 to 1.69 ) in mixed couples showed intermediate mortality levels. All causes of death in the year prior to the pandemic and all other causes of death during the pandemic show little differences between couple constellations. After adjustments (panel B), differences across groups attenuate, but the gradient in COVID-19 mortality remains. Individuals in immigrant-immigrant couples still display the highest HR of dying from COVID-19 relative to the reference group (HR 1.43; 95\% CI 1.29 to 1.58), followed by those in immigrant-native couples (HR 1.24; 95\% CI 1.10 to 1.40 ) and native-immigrant couples (HR $1.15 ; 95 \%$ CI 1.02 to 1.29$)$. It is important to note that there is no statistically significant difference in the risk of COVID-19 mortality between immigrant-native and immigrant-immigrant couples. An opposite gradient is observed with respect to all-cause mortality in the year prior to the pandemic and all other causes of death during the pandemic, with immigrant-immigrant couples displaying the lowest mortality.

Figure 3 is an extension of figure 2 disaggregating the immigrant population by income level of their country of birth (see online supplemental appendix table S3 for estimates). In panel A, there are elevated HRs across all origin groups relative to native-native couples. Immigrants in LMIC-immigrant couples display the highest HR relative to the reference group (HR 3.60; 95\% CI 3.25 to 3.99) followed by those in LMIC-native couples (HR 1.91; $95 \%$ CI 1.42 to 2.57 ). Natives in native-immigrant couples, where HIC and LMIC have been pooled (HR $1.41 ; 95 \%$ CI 1.25 to 1.58 ), HIC-native (HR 1.44; $95 \%$ CI 1.27 to 1.64 ) and immigrants in HIC-immigrant (HR 1.54; 95\% CI 1.34 to 1.77 ) couples display relatively similar HRs. After adjustment (panel B), all groups with an immigrant still display higher HRs relative to native-native couples, but at a lower level. LMIC-immigrant couples experience a particularly strong reduction in their HRs (HR 1.84; $95 \%$ CI 1.62 to 2.09). Compared with LMIC-native couples, their HR remains slightly higher (HR 1.35; 95\% CI 1.00 to 1.82). We also find that HIC-native (HR 1.23; 95\% CI 1.08 to 1.40 ) and HIC-immigrant (HR 1.11; 95\% CI 0.97 to 1.28) couples display higher HRs relative to the reference group.

Sensitivity analyses showed that disaggregating the origin of immigrants in native-immigrant partnerships (online supplemental appendix figure S2) and excluding second-generation Swedes from the Swedish-born population (online supplemental appendix figure S3) produce no further differentials in mortality risks.

\section{DISCUSSION}

Our study shows that immigrants have excess COVID-19 mortality regardless of the origin of their partner, where having a Swedish-born partner is only partially protective against COVID-19 mortality among immigrants from LMIC. These findings challenge hypotheses that poor language proficiency and institutional awareness are major contributing factors explaining the excess mortality from COVID-19 among immigrants.

Language has been considered a vital component of integration and relevant for accessing information for other types of medical treatments and health outcomes. ${ }^{29}$ Given that the COVID-19 pandemic is a unique occurrence that was accompanied by a global diffusion of information, one can argue that even those with presumably little Swedish proficiency have been exposed to recommendations offered in their native languages from either public health officials from their countries of origin or via other international channels. In fact, the information that they may have received from international sources may be more relevant for specific immigrant populations, for example, how to best protect oneself when observing cultural or religious practice. At the same time, the Swedish authorities have translated information to other languages, although not culturally adapted. However, in the first stage of the pandemic, the authorities were delayed in releasing information in all languages and, at least in Stockholm, we found no group differences among intermarried groups and immigrant-immigrant couples (see online supplemental appendix figure S4). This highlights how language is no straightforward factor in mitigating the burden of COVID-19 on immigrant populations.

Prior studies in clinical settings have shown that access to a medical interpreter is associated with better health access and outcomes. ${ }^{29}$ Although we cannot test this 
Table 1 Description of the study population, number, proportion of deaths and death rates

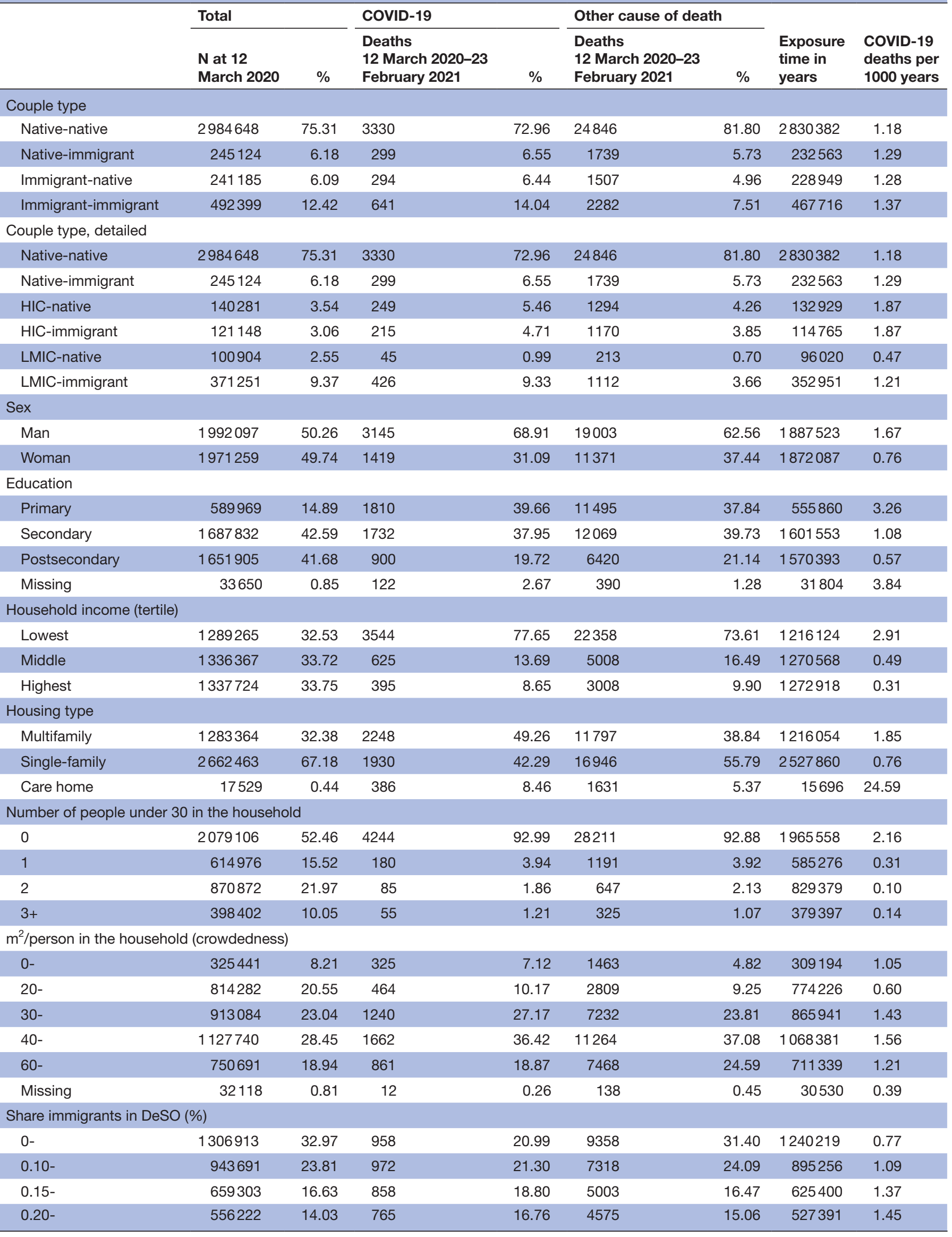


Table 1 Continued

\begin{tabular}{|c|c|c|c|c|c|c|c|c|}
\hline & \multicolumn{2}{|l|}{ Total } & \multicolumn{2}{|l|}{ COVID-19 } & \multicolumn{2}{|c|}{ Other cause of death } & \multirow[b]{2}{*}{$\begin{array}{l}\text { Exposure } \\
\text { time in } \\
\text { years }\end{array}$} & \multirow[b]{2}{*}{$\begin{array}{l}\text { COVID-19 } \\
\text { deaths pe } \\
1000 \text { years }\end{array}$} \\
\hline & $\begin{array}{l}\mathrm{N} \text { at } 12 \\
\text { March } 2020\end{array}$ & $\%$ & $\begin{array}{l}\text { Deaths } \\
12 \text { March 2020-23 } \\
\text { February } 2021\end{array}$ & $\%$ & $\begin{array}{l}\text { Deaths } \\
12 \text { March 2020-23 } \\
\text { February } 2021\end{array}$ & $\%$ & & \\
\hline $0.30-$ & 349234 & 8.81 & 637 & 13.96 & 2896 & 9.53 & 331065 & 1.92 \\
\hline $0.50-$ & 147993 & 3.73 & 374 & 8.19 & 1044 & 3.44 & 140278 & 2.67 \\
\hline Total & 3963356 & 100.0 & 4564 & 100.0 & 30374 & 100.0 & 3759610 & 1.21 \\
\hline
\end{tabular}

HIC, high-income country; LMIC, low-income and middle-income country.

aspect directly, our study shows that immigrants partnered with Swedes are slightly protected with respect to COVID-19 mortality. This suggests that lower language barriers may indeed be relevant with respect to interacting with the healthcare system. To the best of our knowledge, however, we are unaware of any additional provisions provided to non-Swedish speakers at hospitals or clinics during the pandemic.

In addition to disentangling the role of language barriers and lack of understanding of the healthcare system and recommendations in explaining the excess COVID-19 mortality among immigrants, our study provides suggestive evidence that the main explanation is differential exposure to the virus and not susceptibility. ${ }^{20}$ Although it is true that Swedes partnered with a Swede show the lowest mortality, those partnered with an immigrant experience higher COVID-19 mortality. Given that Swedes do not experience language barriers or lack institutional awareness and that biological susceptibility cannot be transmitted between partners, Swedes partnered with immigrants are likely to be at either higher exposure to the virus or impacted by the social susceptibility of their partner. Swedes in mixed partnerships may be exposed to similar social environments and/or risk factors as immigrants thus placing them at a higher risk of exposure as compared to Swedes partnered with another Swede. For example, they may have more transnational contacts or are impacted by some of the same social risk factors as immigrants. Moreover, the higher mortality experienced by natives partnered with immigrants could be related to the disadvantages faced by the immigrant partner either via discrimination or a higher exposure to the pandemic (eg, having a frontline or precarious occupation). Although this type of exposure in mixed partnerships might not be at the same level as for immigrants partnered with another immigrant (as our results with a gradient in mortality suggests).

In this study, immigrants in different family constellations show higher levels of COVID-19 deaths than the majority of natives, after adjustment for a wide range of individual-level and contextual-level factors, including education, income, housing conditions and neighbourhood immigrant density. This set of adjustments also partly accounts for a number of socially patterned chronic health conditions and comorbidities, for example, insulin resistance, hypertension, smoking and obesity, which have been suggested as risk factors for severe cases of COVID-19. ${ }^{17}$

This study has a number of contributions and strengths, First, this is the only study to date to examine
A

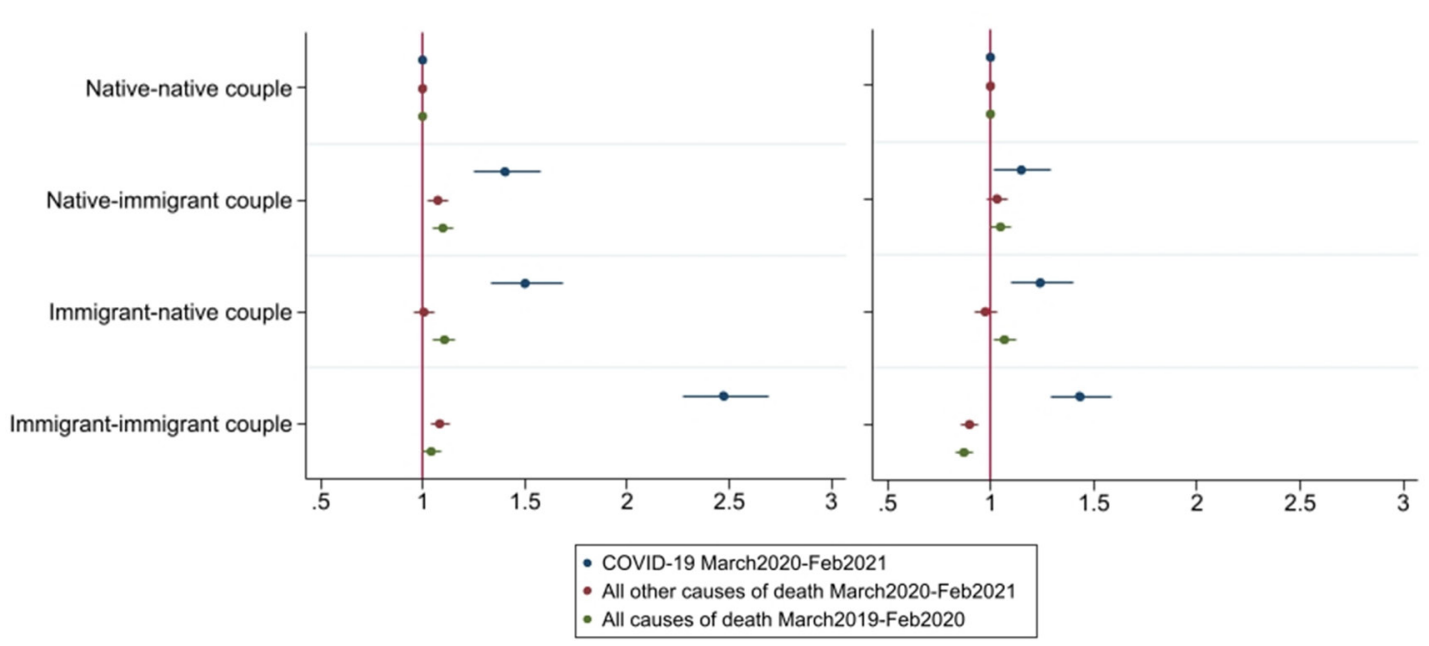

Figure 2 HRs for the risk of dying from COVID-19, other causes of death during the pandemic, and all-cause mortality in the year prior to the pandemic by couple dyad. Model A is adjusted for age and sex only and model B includes full adjustment (reference group: native-native couples). 
A

B

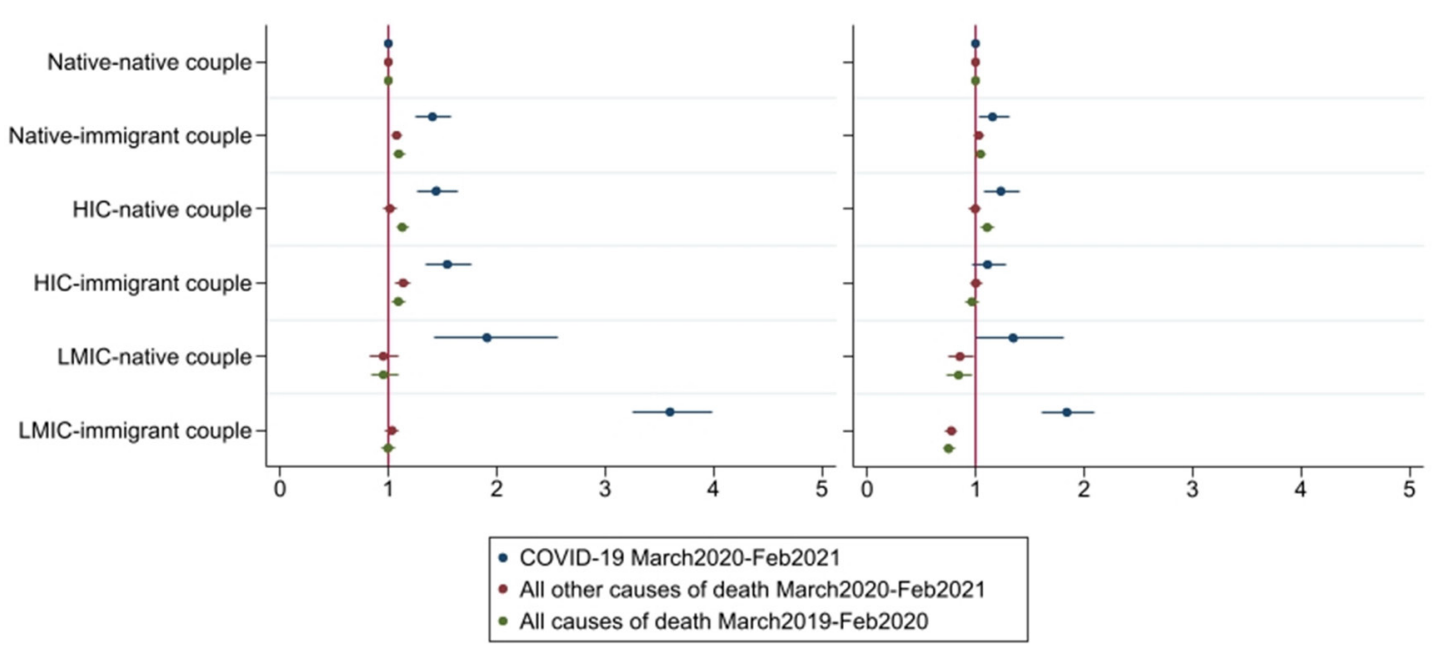

Figure $3 \mathrm{HRs}$ for the risk of dying from COVID-19, other causes of death during the pandemic and all-cause mortality in the year prior to the pandemic by couple dyad disaggregated by low-income and middle-income countries (LMIC) and high-income countries $(\mathrm{HIC}$ ) immigrants. Model $\mathrm{A}$ is adjusted for age and sex only and model $\mathrm{B}$ includes full adjustment (reference group: native-native couples).

sociocultural integration as the mechanism behind the disproportionate burden that COVID-19 has placed on immigrant communities, by comparing the mortality of native-native, immigrant-native and immigrant-immigrant couples in Sweden. A major strength of our study is that we have complete coverage of the total population and all deaths in Sweden from the start of the pandemic until February 2021 for both COVID-19 and remaining causes of death. Thus, our analysis does not suffer from selection into our study population. We have similar highquality data for the year prior to the pandemic, which allows for an unbiased comparison of mortality patterns between the 2 years. The comparison between couple types with respect to mortality from all other causes during the pandemic and all-cause mortality in the year prior strengthens our findings as it demonstrates that the excess mortality from COVID-19 is observed in couples that show no excess mortality from other causes before and during the pandemic.

Despite its strengths, this study has also some limitations that are worth mentioning. Although the Swedish population registers hold high quality and have many advantages, they capture de jure rather than de facto characteristics of individuals. With respect to our measure of partnership, $82 \%$ of the couples in our data are either married or have shared children while the remaining $18 \%$ co-reside unmarried without common children. However, non-marital cohabitation is very common in Sweden, while flat-sharing is not, ${ }^{30}$ and particularly among individuals above their $30 \mathrm{~s}$. It is therefore fair to assume that a substantive share in this remaining group is indeed cohabiting in an amorous relationship, a group that is often overlooked in international studies of health and mortality because of the lack of data. A final limitation is that we do not include information on occupation. Specifically, it has been hypothesised that immigrants are more likely to work in 'frontline' occupations; however, recent research in Sweden has shown that occupational exposure is not a risk factor for COVID-19 mortality. ${ }^{31}$ Furthermore, it is worth noting that a majority of deaths are occurring among retired individuals with no attachment to the labour market.

In conclusion, our study shows that being partnered with a native does not close the gap in COVID-19 mortality with natives even after adjusting for a wide range of possible confounders on individual, couple and residential level. As such, these findings show that lack of awareness of the Swedish recommendations and language barriers are not major drivers for the excess COVID-19 mortality of immigrants. At the same time, the fact that Swedes partnered with immigrants also show excess mortality compared with Swedish couples, suggests that excess mortality among immigrants is explained by differential exposure to the virus.

Acknowledgements We thank Thomas Niedomysl of Region Halland, Petra Westin of the National Board of Health and Welfare and Simon Kurt of Statistics Sweden for their invaluable role in providing the data.

Contributors SA, MB and SJ conceived the study and were responsible for the planning. GA and MB provided the data. MB analysed the data. SA, SJ, SD, EM and MB designed the analysis with contributions from 00, MR, GA. SA, SJ, SD, EM, MB, 00 and MR. GA contributed to the interpretation of the data. SA and SJ drafted the manuscript with substantive contributions from EM, SD, MB, 00, MR and GA. All authors approved the final version of the manuscript.

Funding The Swedish Research Council for Health, Working Life and Welfare (FORTE), grant numbers 2016-07115, 2016-07105, 2016-07128, 2019-00603, The Swedish Research Council (VR), grant number 2018-01825 and The Swedish Foundation for Humanities and Social Sciences (Riksbankens Jubileumsfond), grant M18-0214:1.

Competing interests None declared.

Patient consent for publication Not required.

Ethics approval This study was approved by the Central Ethical Review Board in 2020 (Dnr 2020-02199). 
Provenance and peer review Not commissioned; externally peer reviewed.

Data availability statement This study is produced under the Swedish Statistics Act, where privacy concerns restrict the availability of register data for research. Aggregated data can be made available by the authors, conditional on ethical vetting. The authors access the individual-level data through Statistics Sweden's micro-online access system MONA.

Supplemental material This content has been supplied by the author(s). It has not been vetted by BMJ Publishing Group Limited (BMJ) and may not have been peer-reviewed. Any opinions or recommendations discussed are solely those of the author(s) and are not endorsed by BMJ. BMJ disclaims all liability and responsibility arising from any reliance placed on the content. Where the content includes any translated material, BMJ does not warrant the accuracy and reliability of the translations (including but not limited to local regulations, clinical guidelines, terminology, drug names and drug dosages), and is not responsible for any error and/or omissions arising from translation and adaptation or otherwise.

Open access This is an open access article distributed in accordance with the Creative Commons Attribution 4.0 Unported (CC BY 4.0) license, which permits others to copy, redistribute, remix, transform and build upon this work for any purpose, provided the original work is properly cited, a link to the licence is given, and indication of whether changes were made. See: https://creativecommons.org/ licenses/by/4.0/.

\section{ORCID iDs}

Siddartha Aradhya http://orcid.org/0000-0003-3748-6270

Sol Pía Juárez http://orcid.org/0000-0001-9086-7588

\section{REFERENCES}

1 Pan D, Sze S, Minhas JS, et al. The impact of ethnicity on clinica outcomes in COVID-19: a systematic review. EClinicalMedicine 2020;23:100404.

2 Hayward SE, Deal A, Cheng C, et al. Clinical outcomes and risk factors for COVID-19 among migrant populations in high-income countries: a systematic review. J Migr Health 2021;3:100041.

3 Drefahl S, Wallace M, Mussino E, et al. A population-based cohort study of socio-demographic risk factors for COVID-19 deaths in Sweden. Nat Commun 2020;11:5097.

4 Aldridge RW, Lewer D, Katikireddi SV, et al. Black, Asian and minority ethnic groups in England are at increased risk of death from COVID-19: indirect standardisation of NHS mortality data. Wellcome Open Res 2020;5:88.

5 Rostila M, Cederström A, Wallace M, et al. Disparities in coronavirus disease 2019 mortality by country of birth in Stockholm, Sweden: a Total-Population-Based cohort study. Am J Epidemiol 2021;190:1510-8.

6 Niedzwiedz CL, O'Donnell CA, Jani BD, et al. Ethnic and socioeconomic differences in SARS-CoV-2 infection: prospective cohort study using UK Biobank. BMC Med 2020;18:160.

7 Ross J, Diaz CM, Starrels JL. The disproportionate burden of COVID-19 for immigrants in the Bronx, New York. JAMA Intern Med 2020;180:1043.

8 Millett GA, Jones AT, Benkeser D, et al. Assessing differential impacts of COVID-19 on black communities. Ann Epidemiol 2020;47:S1047279720301769.

9 Williamson EJ, Walker AJ, Bhaskaran K, et al. Factors associated with COVID-19-related death using OpenSAFELY. Nature 2020;584:430-6.

10 Indseth T, Grøsland M, Arnesen T, et al. COVID-19 among immigrants in Norway, notified infections, related hospitalizations and associated mortality: a register-based study. Scand J Public Health 2021;49:48-56.

11 Raharja A, Tamara A, Kok LT. Association between ethnicity and severe COVID-19 disease: a systematic review and meta-analysis. J Racial Ethn Health Disparities 2020;323.

12 Staetsky LD. Elevated Jewish mortality from coronavirus in England and Wales: an epidemiological and demographic detective story. Contemp Jew 2021:1-22.

13 Vanthomme K, Gadeyne S, Lusyne P, et al. A population-based study on mortality among Belgian immigrants during the first COVID-19 wave in Belgium. can demographic and socioeconomic indicators explain differential mortality? SSM Popul Health 2021;14:100797.

14 Statement by the EUPHA Migrant and ethnic minority health section on COVID-19 - CALL FOR ACTION: Reducing the impact of the coronavirus crisis on those 'left behind' - Disadvantaged Migrants and Ethnic Minorities (MEM) 2020.

15 Pareek M, Bangash MN, Pareek N, et al. Ethnicity and COVID-19: an urgent public health research priority. Lancet 2020;395:1421-2.

16 Bhala N, Curry G, Martineau AR, et al. Sharpening the global focus on ethnicity and race in the time of COVID-19. Lancet 2020;395:1673-6.

17 Khunti K, Singh AK, Pareek M, et al. Is ethnicity linked to incidence or outcomes of covid-19? BMJ 2020;369:m1548.

18 Diaz E. Situational brief: migration and Covid-19 in Scandinavian countries, 2020. Available: https://www.migrationandhealth.org/ migration-covid19-briefs

19 Diderichsen F. How did Sweden fail the pandemic? Int J Health Serv 2021;002073142199484:20731421994848.

20 Katikireddi SV, Lal S, Carrol ED, et al. Unequal impact of the COVID-19 crisis on minority ethnic groups: a framework for understanding and addressing inequalities. J Epidemiol Community Health 2021. doi:10.1136/jech-2020-216061. [Epub ahead of print: 21 Apr 2021].

21 Rostila M, Cederström A, Wallace M. Disparities in covid-19 deaths by country of birth in Stockholm, Sweden: a total population based cohort study. Stockholm Research Reports in Demography 2020. doi:10.17045/sthlmuni.12852854.v1

22 Pierre J. Nudges against pandemics: Sweden's COVID-19 containment strategy in perspective. Policy and Society 2020;39:478-93.

23 Paterlini M. 'Closing borders is ridiculous': the epidemiologist behind Sweden's controversial coronavirus strategy. Nature 2020;580:574.

24 Folkhälsomydigheten. Veckorapport Om covid-19, vecka 15, 2020. Available: https://www.folkhalsomyndigheten.se/globalassets/ statistik-uppfoljning/smittsamma-sjukdomar/veckorapporter-covid19/2020/covid-19-veckorapport-vecka-15.pdf

25 Alba RD, Golden RM. Patterns of ethnic marriage in the United States. Social Forces 1986;65:202-23.

26 Lieberson S, Waters MC. Ethnic groups in flux: the changing ethnic responses of American whites. Ann Am Acad Pol Soc Sci 1986;487:79-91.

27 Kalmijn M. Intermarriage and homogamy: causes, patterns, trends. Annu Rev Sociol 1998;24:395-421.

28 The World Bank. GNI, Atlas method (current US\$) | Data. DataBank. Available: https://data.worldbank.org/indicator/NY.GNP.ATLS.CD

29 Flores $\mathrm{G}$. The impact of medical interpreter services on the quality of health care: a systematic review. Med Care Res Rev 2005;62:255-99.

30 SCB. Ensam, Med partner eller kompisboende VaD säger hushållsregistret? 2019. Available: https://www.scb.se/ contentassets/cfe7690018d741798939bd8a6d087219/be0701_ 2015i2018_br_be51br1901.pdf

31 Billingsley S, Brandén M, Aradhya S, et al. Deaths in the frontline: Occupation-specific COVID-19 mortality risks in Sweden. Stockholm Research Reports in Demography 2020. 